\title{
FIVE KEY ELEMENTS FOR A SUSTAINABLE BEACH NOURISHMENT PROGRAM
}

\author{
Timothy W Kana PhD PG, Coastal Science \& Engineering Inc, tkana@coastalscience.com \\ Haiqing L Kaczkowski PhD PE, Coastal Science \& Engineering Inc, hk@coastalscience.com \\ Steven B Traynum, Coastal Science \& Engineering Inc, straynum@coastalscience.com
}

\begin{abstract}
INTRODUCTION at an early stage in each project.

1) Shoreline inventory.

2) Erosion database.

3) Conceptual geomorphic models.

4) Target beach condition.

5) Identify quality borrow sources.
\end{abstract}

Beach nourishment is increasingly the preferred method for maintaining eroding beaches along developed coasts. Although the goal and outcome are generally the same from place to place-add sand and create a wider beachthe underlying causes of erosion tend to be site-specific (Dean 2002). As a result, beach nourishment performance and longevity fluctuate greatly, often with uncertainty of outcome. To increase the probability of success in projects and drawing from 35 years of experience, the authors apply five key elements at the preliminary design phase, which have enabled development of credible plans

The majority of the beach nourishment projects engineered by the authors' firm ( $n=50$, total volume $\sim 27$ million cubic meters) have been constructed in North Carolina and South Carolina (USA), and have been funded by municipalities, counties, and property owner associations with little federal or state assistance. Some have served as interim nourishment designed to maintain beaches while funds for " 50 -year" federal projects are being secured. Others are part of long-term commitments by a community to maintain their beach and property values while reducing potential storm damage.

RATIONALE

The scale of locally funded nourishment projects is often set early in the planning stage and is dictated by limited budgets. Once budgets are set, the only practical way to vary the scope of a project is via reductions or increases in project volume to fit the funds allotted. Construction of nourishment is most often bid as a unit cost of sand delivery plus some fixed cost of equipment mobilization. Developing the project formulation to match budgets and then carrying out projects after one or more years of permitting and reviews leaves a long time of uncertainty before a community knows if their project will be completed as planned.

The five elements for a sustainable nourishment program as listed above are used by the authors to improve the chances of accomplishing the full scale and scope as presented to a community at the initial feasibility stage. The goal is to achieve project formulation and predicted longevity as early as possible and build confidence that such projects will perform as designed.

KEY ELEMENT 1) SHORELINE INVENTORY

States or countries which have an extensive database and detailed studies of coastal erosion and littoral processes have a distinct advantage because this provides a framework to place a prospective nourishment site in a larger context of the regional setting. The authors draw heavily on the rich history of coastal erosion studies in the Carolinas by numerous researchers before developing specific plans for projects. Shoreline inventories should encompass the geologic and geomorphic setting, and principal coastal processes operating in the region.

\section{ELEMENT 2) EROSION DATABASE}

Because nourishment involves volumetric measures, underlying erosion rates should be evaluated in volumetric (not linear) terms. Linear shoreline change rates are generally inadequate predictors of post-nourishment performance. With advances in surveying technology, it is now possible to obtain quality surveys encompassing the entire active littoral zone. Determination of depth of closure (DOC) at a locality is one of the most important parameters for accurate erosion measurements and nourishment predictions.

ELEMENT 3) CONCEPTURAL GEOMORPHIC MODELS The authors develop geomorphic models of sand transport pathways and modes of transport (ie - wave, current, or wave plus current) for project sites using historical data and natural indicators. This helps isolate important signatures of erosion, sources of sediment, and episodic processes such as inlet bypassing. Development of qualitative models forces the project team to take a broad view of a site and demonstrate familiarity with the likely controlling processes via simple graphics for clients.

\section{ELEMENT 4) TARGET BEACH CONDITION}

The condition of any beach is directly related to the volume of sand in the littoral profile. A target, unit beach volume should be developed for each site based on local values for a "healthy" nearby profile (ie - one containing the desired features including adequate dune dimensions, drybeach width, subtidal volume, and sediment quality across the littoral zone) (Kana et al 2015). The target may be limited by funds for restoration but it provides easy-tounderstand parameters for communities to track.

ELEMENT 5) IDENTIFY QUALITY BORROW SOURCES Borrow sources largely control costs of nourishment projects; therefore, it is critical to locate and confirm sources early in the planning process. If sediment-size distribution, not simply mean grain size, closely fits the shape of the native size distribution on the beach, permitting will generally be easier and performance predictions more accurate.

The authors recommend prioritizing for study, whichever element is lacking or weak in a given area. When all five elements are known with confidence, a nourishment project is more likely to perform well and be sustainable.

\section{REFERENCES}

Dean (2002). Beach Nourishment: Theory and Practice. World Scientific, NJ, 399 pp.

Kana, Kaczkowski, and Traynum (2015). An empirical approach to beach nourishment formulation. Chap 4 in YC Kim (ed), Design of Coastal Structures and Sea Defenses, Vol. 2, Series on Coastal and Engineering Practice, World Scientific, pp. 105-144. 